\title{
FILOZOFICZNE I RELIGIJNE KORZENIE NARODOWEGO SOCJALIZMU
}

\author{
Przedhitlerowskie korzenie nazizmu, czyli dusza niemiecka w świetle filozofii i religio- \\ znawstwa. Wprowadzenie i redakcja Bogumił Grott, Olgierd Grott. Warszawa 2018, \\ ss. 206.
}

\section{PHILOSOPHICAL AND RELIGIOUS ROOTS OF NATIONAL SOCIALISM}

\begin{abstract}
Understanding the sources of national socialism requires exploring religious and philosophical sources of German culture. Such research was carried out by Bogdan Suchodolski and Leon Halban, whose work was included in this book. Their research shows that it is necessary to refer to axiological issues when analyzing contemporary political phenomena.
\end{abstract}

Key words: national socialism; German culture; Leon Halban; Bogdan Suchodolski

Streszczenie

Poznanie źródeł narodowego socjalizmu wymaga odniesienia się do religijnych i filozoficznych źródeł kultury niemieckiej. Takie badania przeprowadzili Bogdan Suchodolski oraz Leon Halban, których prace zostały zamieszczone w recenzowanej książce. Ich badania pokazują, że także przy analizowaniu współczesnych zjawisk politycznych konieczne jest sięgnięcie do zagadnień aksjologicznych.

Słowa kluczowe: nazizm; kultura niemiecka: Leon Halban; Bogdan Suchodolski

MACIEJ STRUTYŃSKI Uniwersytet Jagielloński w Krakowie E-mail: strutynski@o2.pl http://orcid.org/0000-0002-7211-4803

CITATION: Strutyński, M. (2020). Filozoficzne i religijne korzenie narodowego socjalizmu. Sprawy Narodowościowe: Seria nowa, 2020(52), Article 2195 https://doi.org/10.11649/sn.2195

This work was supported by the author's own resources. No competing interests have been declared.

This is an Open Access article distributed under the terms of the Creative Commons Attribution 3.0 PL License (creativecommons.org/licenses/by/3.0/pl/), which permits redistribution, commercial and non-commercial, provided that the article is properly cited. (C) The Author(s) 2020

Publisher: Institute of Slavic Studies, Polish Academy of Sciences

Publishing History: Received 2019-12-09; Accepted 2020-12-13; Published 2020-12-23 

ecenzowana pozycja (Grott \& Grott, 2018a) poświęcona jest ideologicznym koncepcjom, które powstały w niemieckim kręgu kulturowym. Koncepcje, powstałe w XIX wieku oraz na początku wieku XX, stworzyły fundament dla ludobójczej ideologii i praktyki narodowego socjalizmu w okresie III Rzeszy.

Koniec II wojny światowej i czasy współczesne przyniosły bogaty zbiór prac naukowych, publicystycznych i innych, które starały się wytłumaczyć genezę ideologii nazistowskiej. Redaktorzy tomu, Bogumił Grott i Olgierd Grott, zauważyli we Wprowadzeniu, że:

Ogrom zbrodni i zniszczeń, jakich dokonała wówczas III Rzesza niemiecka jako państwo i sami Niemcy, wyjątkowo mocno zaangażowani w realizację jego planów, spowodowały niewygasłą po dziś dzień traumę, która zrodziła także obfitą literaturę różnych gatunków. Niedające spokoju pytanie, dlaczego tak się stało i co było głębszą przyczyną tragicznych wydarzeń, nurtuje umysły nie tylko intelektualistów i badaczy naukowych, ale także i zwykłych ludzi, którzy byli świadkami epoki, osobiście doznali krzywd lub spotkały one ich bliskich [...] (Grott \& Grott, 2018b, s. 11).

Próby dotarcia do sedna ideologii niemieckiej i istoty faszyzmu niemieckiego utrudnia ich wielowątkowość. Stawia to przed badaczami dodatkowe przeszkody do pokonania. Faszyzmy europejskie (włoski oraz niemiecki nazizm) stworzyły nową całość z zastanych idei, dokonując ich interpretacji. Maria Zmierczak w artykule Ideologie totalitarne: faszyzm i narodowy socjalizm stwierdziła:

Ci, którzy za wszelką cenę szukają oryginalności faszyzmu, muszą całkiem serio wziąć pod uwage zdanie Georga L.Mosse'a, który napisał, że faszyzm był jak zbieracz odpadków, który stworzył mieszankę ze wszystkiego, co po drodze znalazł i że brak oryginalności wcale nie musiał być przeszkodą na drodze do sukcesu. Lista prekursorów tych idei była bardzo długa - byli to przede wszystkim krytycy rewolucyjnych haseł z 1789 roku, głównie zaś haseł równości i wolności jednostki (Zmierczak, 2006, s. 164).

W niniejszym tomie autorzy zebrali prace dwóch badaczy, Leona Halbana i Bogdana Suchodolskiego, którepowstały stosunkowo niedługo po II wojnie światowej. Jest to zrozumiałe gdyż po zakończeniu niezwykle okrutnej wojny starano się dociec jej przyczyn. Mimo że w historii Polski obecne były konflikty z zachodnim sąsiadem, to wydarzenia II wojny światowej stały się impulsem do poszukiwania wytłumaczenia dla istoty "duszy niemieckiej". Okrucieństwo wojny sprawiło, że zaczęto intensywnie szukać czynnika, który determinuje niemiecką naturę.

Pierwszym z historycznych tekstów zamieszczonych w książce jest praca Bogdana Suchodolskiego Dusza niemiecka w świetle filozofii. Pierwotnie książka ta została opublikowana w 1945 i 1947 roku. Bogdan Suchodolski (1903-1992) był filozofem i historykiem kultury. Z racji swojego wykształcenia starał się dokonać analizy niemieckiej filozofii. Charakterystyczne są jego słowa zamieszczone we wstępie wspomnianej książki. Autorytatywnie stwierdził on, że nie istnieje dwoistość kultury niemieckiej, którą miałaby symbolizować dychotomia Weimaru i Poczdamu. Niemcy filozoficzne i Niemcy militarne, wodzowskie. Suchodolski uważał, że: „(...) dusza niemiecka jest jednolita. I jest właśnie taka, jak to najbardziej bezpośrednio i jaskrawo ujawniają czyny Fryderyka, Bismarcka, Hitlera". (Suchodolski, 2018).

B. Suchodolski wyrażał przekonanie o antyracjonalistycznym i antyempirycznym charakterze filozofii niemieckiej. Tym samym wskazuje na silną tendencję w kulturze niemieckiej odrzucania dziedzictwa Oświecenia.

Ważne miejsce w rozważaniach B. Suchodolskiego zajmuje kwestia (obecna także u L. Halbana) antychrześcijańskiego nastawienia niemieckiej filozofii. Niemiecka krytyka 
i negowanie chrześcijaństwa nie oznaczały wzrostu światopoglądu racjonalistycznego. Tak działo się w innych krajach europejskich. W Niemczech zamiast tego szukano innego wymiaru religijności. Z takiego nastawienia wyniknęło skierowanie się myśli niemieckiej ku wyidealizowanej mitologii przedchrześcijańskich Germanów.

Ponadto zauważa on istniejącą tendencję w Niemczech, aby zastąpić religię rodzimą filozofią. Widział on początek niemieckiej walki z religią w czasach Reformacji Marcina Lutra. Można w tym wyczytać zarzut, że Luter zapoczątkował proces „nacjonalizacji” chrześcijaństwa. Kolejnym krokiem miały być obecne zwłaszcza w dziewiętnastowiecznej ideologii volkistowskiej próby reinterpretacji chrześcijaństwa w duchu niemieckim.

Warto podkreślić, że wiek XIX był niezwykle ważny dla narodzin dwudziestowiecznego narodowego socjalizmu. Rasizm, antysemityzm, walka z chrześcijaństwem silnie się rozwijały w tym okresie stając się żyznym podłożem dla ideologii nazizmu. Na znaczeniu zyskały książki: Paula de Lagarde Deutsche Schriften, w której znalazł się postulat niemieckiego Kościoła narodowego; Artura de Gobineau Szkice o nierówności ras ludzkich, będąca apoteozą idei czystości rasowej; Houstona Stewarta Chamberlaina Die Grundlagen des neunzehnten Jahrhunderts, czerpiąca z idei rasistowskich Gobineau, oraz innych autorów.

Kolejne miejsce w wyborze tekstów zajmują dwie prace Leona Halbana: Mistyczne podstawy narodowego socjalizmu (1946, 1948) oraz Religia starogermańska i jej aktualne znaczenie w Niemczech (1949). Istotne jest to, że L. Halban już w 1936 roku opublikował książkę Religia w Trzeciej Rzeszy, w której bardzo szczegółowo opisał zmiany dokonujące się w Niemczech w sferze religijnej. Autor przed II wojną światową dostrzegał kryzys religijny w Niemczech oraz jego wpływ na niemiecką kulturę.

W pracy Mistyczne podstawy narodowego socjalizmu L. Halban starał się prześledzić nurty ideowe, które jak stwierdzit, „(...) stworzyły tę bardzo znamienną mistykę, znajdującą w końcu swoje ujście polityczne i narzędzie w ruchu narodowosocjalistycznym" (Halban, 2018a, s. 85).

Profesor L. Halban zwracał uwage na dokonywane w Niemczech zmiany w obrębie chrześcijaństwa. Uważał, że niemieckie wywyższanie narodu ma swoje źródło w religijnej koncepcji narodu wybranego i predestynacji. W swojej pracy wykazywał, jak poszczególni niemieccy myśliciele działali w kierunku dokonania sakralizacji narodu niemieckiego. Miało to rzecz jasna znaczące konsekwencje polityczne.

Według L. Halbana u podstaw zmian mentalności stały zmiany, jakie zaszły w niemieckim chrześcijaństwie. Widoczny tam był ruch odwrotu od uniwersalizmu chrześcijańskiego. Należy pamiętać, że w Niemczech od końca XIX wieku obecne były dwie główne tendencje związane z relacjami religii i kwestii narodowej - obie zasadniczo wrogie chrześcijaństwu. Z jednej strony obecny był ruch Deutsche Christen, który w latach trzydziestych XX wieku zdecydowanie opowiadał się za nazizmem. Był to ruch, który dokonywał reinterpretacji chrześcijaństwa (protestantyzmu) w duchu rasistowskim. Idee te narodziły się w nurcie volkistowsko-chrześcijańskim (niemiecki chrystianizm). Jego głównymi cechami było antyuniwersalizm oraz akceptacja rasowego prymatu narodu niemieckiego. Drugim nutem był neopoganizm, który zdecydowanie zrywał z dziedzictwem chrześcijańskim i próbował odtworzyć, a w rzeczywistości stworzyć, niemiecką religię narodową. L. Halban był przekonany, że ten specyficznie rozumiany niemiecki mistycyzm był źródłem barbarzyńskiego okrucieństwa Niemców w trakcie II wojny światowej. Starał się wniknąć jak najgłębiej, szukając odpowiedzi na pytanie o duchowy klimat Niemiec, który doprowadził do niespotykanego zła. 
W drugiej swojej pracy, która została zamieszczona w omawianym tutaj wyborze tekstów, Religia starogermańska i jej aktualne znaczenie w Niemczech (Halban, 2018b), oprócz treści obecnych także we wcześniej omówionej pracy, L. Halban wyraźnie akcentuje obecność wątków przedchrześcijańskich w kulturze i ideologii niemieckiej. Tym samym uznaje, że brak dominującego pierwiastka chrześcijańskiego spowodował, że Niemcy nie byli ograniczani w działaniach politycznych przez etyką chrześcijańską.

W konkluzji warto podkreślić, że dobrze się stało, iż wspomniane prace zostały przypomniane współczesnemu czytelnikowi. Pokazują one wagę relacji pomiędzy ideami religijnymi a ideami politycznymi. Pozwalają na uświadomienie roli religii w życiu politycznym świata. B. Suchodolski i L. Halban starali się pokazać, że w kulturze niemieckiej obecne były silne pierwiastki antyhumanistyczne, które doprowadziły do zbrodni niemieckich na Żydach, Polakach i innych narodach europejskich. Ponadto, prace te przypominają również, że zbrodnicze idee narodziły się w określonej kulturze konkretnego narodu, a nie niedookreślonych "nazistów". Jest to też przestroga przed próbami relatywizowania historii.

\section{BIBLIOGRAFIA}

Grott, B., \& Grott, O. (Red.). (2018a). Przedhitlerowskie korzenie nazizmu, czyli dusza niemiecka w świetle filozofii i religioznawstwa. Von Borowiecky.

Grott, B., \& Grott, O. (2018b). Wprowadzenie. W B. Grott \& O. Grott (Red.), Przedhitlerowskie korzenie nazizmu, czyli dusza niemiecka w świetle filozofii i religioznawstwa. Von Borowiecky.

Halban, L. (2018a). Mistyczne podstawy narodowego socjalizmu. W B. Grott \& O. Grott (Red.), Przedhitlerowskie korzenie nazizmu, czyli dusza niemiecka w świetle filozofii i religioznawstwa. Von Borowiecky.

Halban, L. (2018b). Religia starogermańska i jej aktualne znaczenie w Niemczech. W B. Grott \& O. Grott (Red.), Przedhitlerowskie korzenie nazizmu, czyli dusza niemiecka w świetle filozofii i religioznawstwa. Von Borowiecky.

Suchodolski, B. (2018). Dusza niemiecka w świetle filozofii. W B. Grott \& O. Grott (Red.), Przedhitlerowskie korzenie nazizmu, czyli dusza niemiecka w świetle filozofii i religioznawstwa. Von Borowiecky.

Zmierczak, M. (2006). Ideologie totalitarne: faszyzm i narodowy socjalizm. W M. Kuniński (Red.), Totalitaryzm a tradycja zachodnia. Ośrodek Myśli Politycznej; Księgarnia Akademicka. 